\title{
Forklift Alternatiflerinin KEMIRA-M Yöntemi ile Değerlendirilmesi
}

\author{
Gizem SARIÇALI ${ }^{*}$, Nilsen KUNDAKCI ${ }^{* *}$ \\ ÖZ
}

İşletmelerde, insan gücünün yetmediği ağır yüklerin kaldırılması, istenilen yerlere götürülmesi ve uygun yerlere istiflenmesi için genellikle forkliftler kullanılmaktadır. Depoların aktif kullanımının sağlanması için depoların fiziki şartlarına uygun forkliftin seçilmesi önemlidir. Bu çalışmada bir tekstil işletmesinde depolamada kullanılacak forklift alternatiflerinin değerlendirilerek işletme açısından en uygun olan forkliftin belirlenmesinde yeni bir Çok Kriterli Karar Verme (ÇKKV) yöntemi olan KEMIRA-M (KEmeny Median Indicator Rank Accordance-Modified) yöntemi kullanılmıştır. Bu yöntem çok fazla başlangıç bilgisi gerektirmemekte, bu açıdan kriterlerin ağırlıklarını belirlemede ve en uygun alternatifin seçiminde kullanılabilmektedir. Çalışmanın sonucunda tekstil işletmesinin ihtiyaçlarını en iyi karşılayacak forklift alternatifi KEMIRA-M yöntemi ile belirlenerek işletmeye karar alma sürecinde yardımcı olunmuştur.

Anahtar Kelimeler: Çok Kriterli Karar Verme (ÇKKV), KEMIRA-M Yöntemi, Forklift Seçimi

\author{
JEL Sinıflandırması: C02, C44
}

\section{Evaluation of Forklift Alternatives with KEMIRA-M method}

\begin{abstract}
Businesses generally uses forklifts for lifting, stacking and transporting to the desired location of heavy loads in case of human power is not enough. It is important to select suitable forklifts for the physical conditions of the warehouses in order to ensure the active use of them. In storage, the selection of the appropriate forklift for physical conditions of the warehouse is important to use warehouses effectively. In this study, KEMIRA-M (KEmeny Median Indicator Rank Accordance-Modified) method, which is a new Multi-Criteria Decision Making (MCDM) method, was used to evaluate forklift alternatives to be used in storage and to determine the most appropriate forklift for the textile company. This method does not require much initial information, so it can be used to determine the weights of the criteria and to select the most appropriate alternative. As a result of the study, forklift alternative that will best meet the needs of the textile company was determined with KEMIRA-M method, by this way the company has been aided during the decision process.
\end{abstract}

Keywords: Multi-Criteria Decision Making (MCDM), KEMIRA-M Method, Forklift Selection

JEL Classification: C02, C44

Geliş Tarihi /Received: 19.07.2016 Kabul Tarihi / Accepted: 20.10.2016

\footnotetext{
Pamukkale Üniversitesi, Sosyal Bilimler Enstitüsü, Sayısal Yöntemler Yüksek Lisans Programı, gzemmsaricali@hotmail.com

Yrd. Doç. Dr., Pamukkale Üniversitesi, İ̈BF, İşletme Bölümü, Sayısal Yöntemler Ana Bilim Dalı, nilsenk@pau.edu.tr
} 


\section{GİRISŞ}

İşletmelerde depoların aktif kullanımı; ürünün üretimi öncesinde hammadde stoklarının yeterince elde bulundurulabilmesi ve ürünün üretim safhasından sonra dağıtım aşamasına kadar tutulabilmesi açısından önemlidir. İnsan gücünün yetmediği ağırlıkların kaldırılması ve insanların ulaşamadığı yükseklikteki rafların kullanılabilmesi için depolarda forkliftler sıklıkla kullanılmaktadır. Depolama yöntemi tedarik süreçlerinde önemli bir role sahiptir. Bu açıdan, depolarda kullanılan forkliftlerin seçimi maliyet, işin sürekliliğinin sağlanması, iş güvenliği, çalışma alanının verimli kullanımı açısından önemlidir. Dolayısı ile depolarda kullanımı ön planda olan forkliftlerin seçimi de önem kazanmaktadır. Forklift seçim sürecinde birden çok alternatif çok sayıda kriter altında değerlendirilmektedir. Bu durumlarda çok kriterli karar verme yöntemleri kullanılabilmektedir. Bu çalışmada, forklift alternatiflerinin değerlendirilerek en uygununun seçilmesinde Çok Kriterli Karar Verme (ÇKKV) yöntemi KEMIRA-M (KEmeny Median Indicator Rank Accordance-Modified) kullanılmıştır.

Literatürde malzeme taşıma ekipmanlarından biri olan forkliftlerin seçiminde farklı yöntemlerden yararlanan çalışmalar yer almaktadır. Park (1996), malzeme taşıma ekipmanlarının seçimi ve değerlendirilmesi için dört modülden oluşan zeki bir sistem geliştirmiştir. İlk modül uygun ekipman tipinin belirlenmesine yardımcı olan veri tabanından oluşur. İkinci modül, ekipman cinsinin seçiminde kullanılacak çok kriterli karar verme sürecini içerir. Üçüncü modül, ekipman tiplerinin modellerini ve özelliklerini içeren veri tabanından oluşur. Dördüncü son modül ise ekipman modellerinin performanslarını değerlendirmek için yapılan simülasyonları içerir. Önerilen zeki sistem yardımıyla işletmeler için en uygun malzeme taşıma ekipmanlarının belirlenmesi amaçlanmıştır. Yaman (2001), malzeme taşıma ekipmanları seçimi ve malzeme taşıma sistemi ön tasarım problemlerinin tanımlanması için bilgi tabanlı bir sistem geliştirmiştir. $\mathrm{Bu}$ sistem ile ekipmanlara aşina olmayan tasarımcılara uygun ekipmanın seçiminde yardım etmeyi amaçlamıştır. Çalışmanın sonunda, önermiş olduğu sistemin işlerliğini bir örnek üzerinde göstermiştir. Kulak (2005), malzeme taşıma ekipmanı seçimi için bulanık çok kriterli karar vermeye dayanan bir karar destek sistemi geliştirmiştir. Bu sistem veri tabanı, kural tabanlı sistem ve çok kriterli karar verme modüllerinden oluşur. Veri tabanı, ekipman türleri ve özellikleri hakkında detaylı verileri içerir. Kural tabanlı sistem modülü, en uygun malzeme taşıma ekipmanı tipini belirlemek için çıkarsama motoru tarafından kullanılan kuralları oluşturur. Sonuçta, aksiyomatik tasarım ilkeleri ve bilgi aksiyomu kullanılarak alternatifler arasından en uygun ekipman belirlenir. Onut vd. (2009), malzeme taşıma ekipmanları seçimi için bulanık ANP (Analytic Network Process) ve bulanık TOPSIS (Technique for Order Preference by Similarity to Ideal Solution) yöntemlerini bir arada kullanmışlardır. Bulanık ANP ile kriterlerin ağırlıklarını belirlemişler, en uygun ekipmanın seçiminde ise bulanık TOPSIS yönteminden yararlanmışladır. Hassan (2010), malzeme taşıma ekipmanı seçimi için 10 aşamadan oluşan bir çerçeve sunmuştur. İlgili ekipmanların seçiminde izlenecek aşamaları ayrıntılı bir şekilde açıklayarak tesisi tasarlayan karar vericilere ve endüstriyel yöneticilere yol göstermeyi amaçlamıştır. Atanasković vd. (2011), depolarda kullanılacak forkliftin seçilmesinde çok kriterli karar verme yöntemlerinden yararlanmışladır. Kriterlerin değerlendirilerek ağırlıklarının belirlenmesinde Delphi yöntemini kullanmışlar, VIKOR (Višekriterijumsko Kompromisno Rangiranje) yöntemi ile de forklift alternatiflerini sıralayarak en uygun olanı seçmişlerdir. Pamučar ve Ćirović, (2015), lojistik merkezlerinde kullanılmak üzere forklift satın alma sürecinde DEMATEL (Decision Making Trial and Evaluation Laboratory) ve MABAC (Multi-Attributive Border Approximation Area Comparison) yöntemlerinden yararlanmışlardır. DEMATEL yöntemi ile kriter ağırlıklarını belirledikten sonra, forklift alternatiflerini değerlendirerek en uygun alternatifin seçilmesinde yeni bir yöntem olan MABAC yöntemini kullanmışlardır. Elde ettikleri sonuçları farklı ÇKKV yöntemleri ile elde edilen sonuçlar ile karşılaştırmışlar ve önermiş oldukları yöntemin uygulanabilir olduğunu belirtmişlerdir. 
$\mathrm{Bu}$ çalışmada ise forklift seçimi için KEMIRA-M yönteminin kullanılması önerilmiştir. KEMIRA yöntemi yeni bir yöntem olması nedeniyle literatürde bu yöntemi uygulayan çok sayıda çalışma yoktur. KEMIRA yöntemi ilk kez Krylovas vd. (2014) tarafından önerilmiştir. Daha sonra, Kosareva vd. (2016), KEMIRA yöntemi ile güvenlik elemanı alımı için personel seçim problemini ele almışlardır. 12 güvenlik görevlisi alternatifi, belirlenen kriterler altında KEMIRA yöntemi ile değerlendirilmiştir. Yazarlar bu yöntemin personel seçimine uygun olduğu gibi diğer çok kriterli karar verme problemlerinin çözümünde kullanılabileceğini belirtmişlerdir. Ayrıca KEMIRA yöntemi Krylovas vd. (2016) tarafindan modifiye edilerek KEMIRA-M yöntemi geliştirilmiştir. Bu yöntemi Vilnius şehrindeki tehlikeli olmayan atıkları yakarak imha eden fabrika için yer seçiminde kullanmışlar ve 7 alternatif arasından en iyi fabrika yerini belirlemişlerdir. Çalı̧̧manın sonuç kısmında KEMIRA-M yönteminin kentsel planlamada ÇKKV problemlerini çözmede uygun olduğu belirtilmiştir. Ayrıca, diğer ÇKKV yöntemlerine göre daha az başlangıç bilgisi gerektirdiği için bilgi toplamanın zor veya oldukça pahalı olduğu durumlarda KEMIRA-M yönteminin uygulanabilir olduğuna değinilmiştir.

$\mathrm{Bu}$ çalışmada KEMIRA yöntemini ele alan literatürdeki diğer çalışmalardan farklı olarak bir tekstil işletmesinde kullanılmak üzere forklift alternatifleri değerlendirilmiş ve işletme için en uygunu seçilmiştir. Bu çalışma iki açıdan özgünlüğe sahiptir; bunlardan ilki ülkemizde KEMIRA-M yöntemini ele alan başka bir çalışmaya rastlanmamış olması, ikincisi ise forklift seçimi gibi farklı bir alana uygulanmasıdır.

Çalışmanın ikinci bölümünde KEMIRA-M yöntemi açıklanmış ve yönteme ilişkin adımlara yer verilmiştir. Üçüncü bölümde, KEMIRA-M yönteminin uygulanabilirliğini göstermek için, bir tekstil işletmesinin forklift seçim problemi ele alınmış ve işletme için en uygun alternatif belirlenmiştir. Son bölümde ise sonuç ve önerilere yer verilerek gelecek çalışmalar için önerilerde bulunulmuştur.

\section{KEMIRA-M YÖNTEMI}

Vilnius Gemidiminas Teknik Üniversitesi araştırmacıları Zavadskas, Kosareva ve Dadelo 2014 yılında çok kriterli karar verme yöntemi olan KEMIRA (KEmeny Median Indicator Rank Accordance) yöntemini geliştirmişlerdir. Olası seçeneklerden en iyi alternatifi belirlemek için kullanılan yeni bir yöntemdir. KEMIRA yöntemi öncelikle kriterlerin önceliklerini ve ağırlıklarını belirlemeyi amaçlamaktadır. Yöntem çok fazla başlangıç bilgisi gerektirmemektedir ve bu yöntem optimizasyon probleminin çözümünü bulmaya dayanır.

ÇKKV probleminin çözüm sürecine geçilmeden önce kriterler kendi içinde iki veya daha fazla gruba (iç faktörler, dış faktörler) ayrılır. Bu şekilde bir ayrım yapılmasının nedeni özellikle kriter sayısı fazla olduğunda işlemlerde kolaylık sağlamaktır. Aksi takdirde KEMIRA-M yönteminde yapılan hesaplamalarda kullanılan ikili kıyaslamalar ve matris işlemleri karmaşık hale gelecektir. Bu nedenle yöntemi öneren yazarlar kriterler arasında bir ayrıma gitmişlerdir. Sonraki aşamada, alanındaki uzman kişilerin değerlendirmeleri sonucu kriterlerin önceliklerinin belirlenmesi amaçlanır. Bunun için Kemeny Medyan (Kemeny Median) yöntemi kullanılır (Kosareva vd, 2016:53). Bu süreçte sadece uzmanlar tarafından belirlenen kriterlerin öncelik siralamasından yararlanılmaktadır.

Problemin çözümünün ikinci aşamasında ise kriterlerin ağırlıkları belirlenir. Kriterlerin ağırlıklarını belirlemek için Sıralama Uygunluk Göstergesi (Indicator Rank Accordance) yöntemi kullanılır (Kosareva vd, 2016:51). Bu yöntem tümüyle hesaplamalara dayanır ve uzman değerlendirmesi gerektirmez. Kriterlerin ağırlıkları belirlendikten sonra, üçüncü aşamada her alternatif için amaç fonksiyon değerleri hesaplanır ve alternatifler bu değerlere göre sıralanır. 
KEMIRA-M yöntemi, KEMIRA yönteminin modifiye edilmiş şekli olup bu yöntemde izlenecek adımlar şu şekilde özetlenebilir:

1.Adım: Öncelikle, karar matrisi Eşitlik (1)'de görüldüğü gibi oluşturulur.

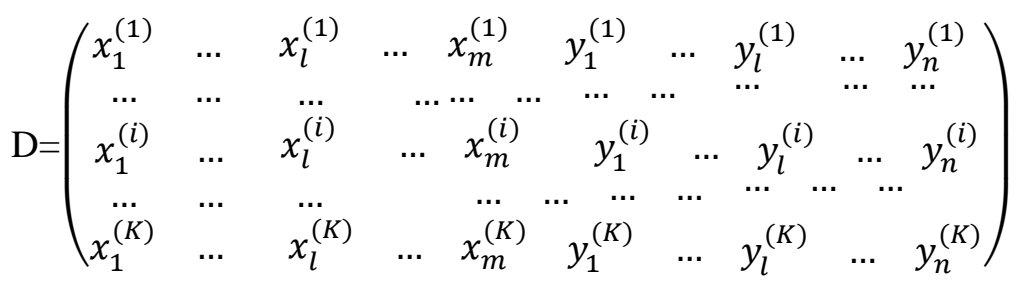

Bu karar matrisinde, $i$ alternatifleri göstermekte $(i=1, \ldots, K)$ ve $x_{j}^{(i)}, i$. alternatifin $j$. $(j=1, \ldots, m)$ iç kriter için aldığ 1 değeri, $y_{j^{\prime}}^{(i)}$ ise $i$. alternatifin $j^{\prime}\left(j^{\prime}=1, \ldots, n\right)$ dış kriter için aldığ 1 değeri ifade etmektedir (Kosareva vd., 2016:54).

2. Adım: Uzmanlar tarafindan belirlenen kriter tercihleri tablosu oluşturulur.

\begin{tabular}{|c|ccccc|ccccc|}
\hline Uzman & $\boldsymbol{x}_{\mathbf{1}}$ & $\ldots$ & $\boldsymbol{x}_{\boldsymbol{l}}$ & $\ldots$ & $\boldsymbol{x}_{\boldsymbol{m}}$ & $\boldsymbol{y}_{\mathbf{1}}$ & $\ldots$ & $\boldsymbol{y}_{\boldsymbol{l}}$ & $\ldots$ & $\boldsymbol{y}_{\boldsymbol{n}}$ \\
\hline $\mathbf{1}$ & $j_{1}^{(1)}$ & $\ldots$ & $j_{l}^{(1)}$ & $\ldots$ & $j_{m}^{(1)}$ & $j^{\prime(1)}$ & $\ldots$ & $j_{l}^{\prime(1)}$ & $\ldots$ & $j_{n}^{\prime(1)}$ \\
$\ldots$ & $\ldots$ & $\ldots$ & $\ldots$ & $\ldots$ & $\ldots$ & $\ldots$ & $\ldots$ & $\ldots$ & $\ldots$ & $\ldots$ \\
$\mathbf{s}$ & $j_{1}^{(s)}$ & $\ldots$ & $j_{l}^{(s)}$ & $\ldots$ & $j_{m}^{(s)}$ & $j^{\prime(s)}$ & $\ldots$ & $j_{l}^{\prime(s)}$ & $\ldots$ & $j_{n}^{\prime(s)}$ \\
$\ldots$ & $\ldots$ & $\ldots$ & $\ldots$ & $\ldots$ & $\ldots$ & $\ldots$ & $\ldots$ & $\ldots$ & $\ldots$ & $\ldots$ \\
$\mathbf{S}$ & $j_{1}^{(S)}$ & $\ldots$ & $j_{l}^{(S)}$ & $\ldots$ & $j_{m}^{(S)}$ & $j_{1}^{\prime(S)}$ & $\ldots$ & $j_{l}^{\prime(S)}$ & $\ldots$ & $j_{n}^{\prime(S)}$ \\
\hline
\end{tabular}

Bu tabloda $S(s=1,2 \ldots, S)$ uzman sayısını ifade etmektedir (Kosareva vd., 2016:54).

3. Adım: Eşitlik (1)'deki karar matrisinde $x_{j}$ veya $y_{j^{\prime}}$ kriterleri minimize edilmesi gereken kriterler (maliyet kriteri) ise, bu kriterlere ait alternatif değerleri $\frac{1}{x_{j}^{(i)}}$ veya $\frac{1}{y_{j^{\prime}}^{(i)}}$ şeklinde yeniden yazılarak, yeni bir matris oluşturulur (Krylovas vd., 2016:54; Jahan vd., 2016:87).

4. Adım: Adım (3)'te elde edilen yeni matristeki değerler kullanılarak Eşitlik (3) yardımıyla normalize edilmiş karar matrisi oluşturulur.

$$
x_{j}^{(i) *}=\frac{x_{j}^{(i)}-x_{\min }^{(i)}}{x_{\max }^{(i)}-x_{\min }^{(i)}}, y_{j^{\prime}}^{(i) *}=\frac{y_{j^{\prime}}^{(i)}-y_{\min }^{(i)}}{y_{\max }^{(i)}-y_{\min }^{(i)}}, i=1,2, \ldots K
$$

5. Adım: Kemeny Medyan Yöntemi ile kriterlerin öncelikleri belirlenir. $S(s=1,2, \ldots, S)$ uzman tarafindan belirlenen $X=\left(x_{1}, x_{2}, \ldots x_{m}\right)$ ve $Y=\left(y_{1}, y_{2}, \ldots, y_{n}\right)$ kriterleri öncelik sirasina göre büyükten küçüğe doğru sıralanır. Uzmanlar tarafından belirlenen kriter öncelikleri sıralamalarını birleştirerek tek bir sıralama elde etmek için Kemeny Medyan yöntemi kullanılır. 
Kemeny Medyan yönteminde, $S(s=1,2, \ldots, S)$ uzman tarafindan belirlenen $X=\left(x_{1}, x_{2}, \ldots, x_{m}\right)$ kriteri öncelik sırasına göre büyükten küçüğe doğru siralandıktan sonra,

$$
a_{j k}= \begin{cases}0, & \text { ĕg } e r x_{j}<x_{k} \\ 1, & \text { e } \text { er } x_{j}>x_{k}\end{cases}
$$

$r=1,2, \ldots, S$ şeklinde olan $A^{(r)}=\left(a_{j k}\right)_{m x m}$ kare matrisi oluşturulur. Oluşturulan kare matrisin köşegen elemanları sıfıra eşittir, $x_{j j}=0, j=1,2, \ldots, m$ ayrıca $a_{j k}=1-a_{k j}, j \neq k$ dir (Krylovas vd., 2016:57).

Örneğin, bu çalışmadaki uygulamada $U_{1}$ uzmanı tarafından belirlenen $X$ kriter önceliği sıralaması $\quad x_{3}>x_{1}>x_{2}$ şeklinde oluşturulmuştur. Eşitlik (4) yardımıyla $A^{(1)}=\left(\begin{array}{lll}0 & 1 & 0 \\ 0 & 0 & 0 \\ 1 & 1 & 0\end{array}\right)_{3 \times 3}$ kare matrisi elde edilir. Benzer şekilde, her bir uzman tarafindan belirlenen $X$ kriter önceliği sıralamasına göre Eşitlik (4) yardımıyla kare matris şeklinde ifade edilir.

$A^{(r)}, A^{(s)}$ matrisleri tarafından tanımlanan iki farklı sıralama arasındaki uzaklığın ölçümü Eşitlik (5)'te gösterilmiştir (Krylovas vd., 2016:57).

$$
\rho\left(A^{(r)}, A^{(s)}\right)=\sum_{j=1}^{m} \sum_{k=1}^{m}\left|a_{j k}^{(r)}-a_{j k}^{(s)}\right|
$$

Eşitlik (5)'teki $m$ değeri $x_{1}, x_{2}, \ldots, x_{m}$ kriterlerinin sayısını göstermektedir.

Örneğin, bu çalışmadaki uygulamada;

$U_{1}$ uzmanı tarafından belirlenen $X$ kriter önceliği matrisi $A^{(1)}=\left(\begin{array}{lll}0 & 1 & 0 \\ 0 & 0 & 0 \\ 1 & 1 & 0\end{array}\right)_{3 \times 3}$

ve $U_{2}$ uzmanı tarafından belirlenen $X$ kriter önceliği matrisi $A^{(2)}=\left(\begin{array}{lll}0 & 1 & 1 \\ 0 & 0 & 1 \\ 0 & 0 & 0\end{array}\right)_{3 \times 3}$ şeklinde elde edilmiştir. Eşitlik (5) yardımıyla

$$
\begin{aligned}
\rho\left(A^{(1)}, A^{(2)}\right)= & |0-0|+|1-1|+|0-1|+|0-0|+|0-0|+|0-1|+|1-0|+|1-0| \\
& +|0-0|=4
\end{aligned}
$$

elde edilir.

$S$ tane uzman tarafindan $A^{(1)}, A^{(2)}, \ldots, A^{(s)}$ öncelik kriteri matrislerinin oluşturulduğu varsayılsın. Bu matrislerden $A^{(M)}$ medyan matrisi Eşitlik (6) yardımıyla elde edilir (Kosareva vd., 2016:55).

$$
A=A^{(M)}=\arg { }_{A}^{\min } \sum_{s=1}^{S} \rho\left(A, A^{(s)}\right)
$$

Burada elde edilen toplamın minimum değeri alınır. Eşitlik (6) yardımı ile elde edilen sonuç sayesinde kriter öncelikleri Kemeny Medyan Yöntemi ile belirlenmiş olur. Kemeny Medyan Yöntemi ile $X=\left(x_{1}, x_{2}, \ldots x_{m}\right)$ kriter önceliğini belirlemede kullanılan adımların aynısı $Y=\left(y_{1}, y_{2}, \ldots, y_{n}\right)$ kriter önceliğini belirlemede de kullanılır. 
6. Adım: Modifiye edilmiş Sıralama Uygunluk Göstergesi (Indicator Rank Accordance) yöntemi ile ağırlıklar hesaplanır ve alternatifler sıralanır.

Kriter öncelikleri 5. Adımda belirlendikten sonra kriterlerin ağırlıkları belirlenir. Kriter ağırlıklarını belirlemede Sıralama Uygunluk Göstergesi yöntemi kullanılır. Bu adımda her bir kriter için ağırlık katsayıları bulunur. Ağırlık katsayıları bulunmadan önce 5. Adımda Kemeny Medyan Yöntemi ile belirlenen kriter öncelikleri sıralamasına göre, kriterler büyükten küçüğe doğru siralanır.

Örneğin, bu çalışmadaki uygulamada Kemeny Medyan Yöntemiyle elde edilen $X=\left(x_{1}, x_{2}, \ldots, x_{m}\right) \quad(m=3) \quad$ ve $Y=\left(y_{1}, y_{2}, \ldots, y_{n}\right) \quad(n=4)$ kriter öncelikleri Eşitlik (7)'de gösterilmiştir.

$$
x_{1}>x_{2}>x_{3} \text { ve } y_{4}>y_{3}>y_{2}>y_{1}
$$

Eşitlik (7)'deki öncelik sırasına göre kriterlerin ağırlıklarının sıralaması Eşitlik (8)'de gösterilmiştir.

$$
w_{x_{1}} \geq w_{x_{2}} \geq w_{x_{3}} \geq 0 \quad \text { ve } \quad w_{y_{4}} \geq w_{y_{3}} \geq w_{y_{2}} \geq w_{y_{1}} \geq 0
$$

Eşitlik (8)'deki kriter ağırlıkları Eşitlik (9)'da belirtilen şartları sağlar.

$$
w_{x_{j}}, w_{y_{j^{\prime}}} \in[0 ; 1] \quad \text { ve } w_{x_{1}}+w_{x_{2}}+w_{x_{3}}=1, \quad w_{y_{1}}+w_{y_{2}}+w_{y_{3}}+w_{y_{4}}=1
$$

Her bir kriter için ağırlık katsayıları bulunurken Eşitlik (8)'de oluşturulan kriter ağırlıkları sıralamasına göre ve ağırlıklar toplamı 1'e eşit olacak şekilde ağırlık katsayı kombinasyon tablosu oluşturulur.

Alternatiflerin siralamas1, her bir alternatif için hesaplanan $X_{w_{x}}(a)+Y_{w_{y}}(a)$ lineer kombinasyonlarının toplam değerlerine göre belirlenir. $X_{w_{x}}(a)$ ve $Y_{w_{y}}(a)$ değerleri Eşitlik (10) yardımıyla bulunur (Krylovas vd., 2016:59).

$$
X_{W_{x}}(a)=\sum_{j=1}^{m} w_{x_{j}} x_{j}^{*}(a), \quad Y_{W_{y}}(a)=\sum_{j^{\prime}=1}^{n} w_{y_{j^{\prime}}} y_{j^{\prime}}^{*}(a)
$$

Buradaki $x_{j}^{*}(a)$ ve $y_{j^{\prime}}^{*}(a)$ değerleri Eşitlik (3) kullanılarak elde edilir. Geliştirilmiş Sıralama Uygunluk Göstergesi (Modified Indicator Rank Accordance) yönteminin amac1 $X_{w_{x}}(a)$ ve $Y_{w_{y}}(a)$ değerlerine yakın $w_{x}=\left(w_{x_{1}}, w_{x_{2}}, \ldots w_{x_{m}}\right)$ ve $w_{y}=\left(w_{y_{1}}, w_{y_{2}}, \ldots w_{y_{n}}\right)$ katsayı değerlerini seçmektir. Bunun için de Eşitlik (11)'den yararlanılır (Krylovas vd., 2016:60).

$$
F(X, Y)=\min w_{x}, w_{y} \sum_{a}\left|X_{w_{x}}(a)-Y_{w_{y}}(a)\right|
$$

Eşitlik (11)'deki toplam bütün alternatifler için uygulanır ve aralarından minimum değer seçilir.

KEMIRA yöntemi ile KEMIRA-M yönteminin ana amacı ve izledikleri yollar aynı olmasına rağmen aralarında bir takım farklılıklar bulunmaktadır. KEMIRA yönteminde Eşitlik (11)'de gösterilen formülde $X_{w_{x}}(a)$ ve $Y_{w_{y}}(a)$ değerlerinin farkları toplamının en küçük değerini bulmak yerine bu değerlerin farklarının kareleri toplamının en küçük değeri elde edilir. KEMIRA-M yöntemini KEMIRA yönteminden ayıran bir diğer farkta şudur ki; Eşitlik (11)'deki toplam bütün alternatifler için uygulanırken, KEMIRA'da ise toplam sadece en iyi alternatif için hesaplanır (Krylovas vd., 2016:60). 


\section{UYGULAMA}

Bu çalışmada bir tekstil işletmesi deposunda kullanılacak forklift seçimi için alternatifler KEMIRA-M yöntemi ile değerlendirilmiş ve işletmeye en uygun forklift belirlenmiştir. Tekstil işletmesi deposunda kullanılmak üzere kapalı depo şartlarına uygun 3 ton kaldırma kapasiteli akülü forklift alım sürecinde 10 farklı markadan oluşan alternatifler, 7 kriter altında değerlendirilmiştir. Forklift seçiminde alternatiflerin değerlendirilmesinde ele alınan kriterler; dış dönüş yarıçapı, asansör yüksekliği, üst koruyucu yüksekliği, forkliftin fiyatı, marka güvenirliği, servis ağı ve garanti süresidir. Bu kriterlerden, dış dönüş yarıçapı ve kaldırma yüksekliği, deponun aktif ve verimli şekilde kullanımı açısından önemlidir. Depo yüksekliğine uygun olarak yapılan rafların tamamının kullanılabilmesi için kaldırma yüksekliği deponun fiziki özelliklerine uygun olmalıdır. Dış dönüş yarıçapının önemi ise depoda raflar arası mesafenin daha çok forkliftin hareket mesafesine uygun düzenlemesi gerekliliğindendir. Bir başka ifadeyle, alınacak forklift ne kadar az çalışma alanına ihtiyaç duyarsa, deponun kapasitesi o kadar verimli kullanılabilir. Üst koruma yüksekliği ise işçinin forklift ile çalışması sırasında rahat çalışma alanının sağlanması için ve oluşabilecek kazalardan korunması açısından önemlidir. Forkliftin seçiminde işletmeler maliyet açısından fiyat ve garanti süresini, sermayenin verimli şekilde kullanılıp karın yüksek seviyede tutulabilmesi için göz önüne almaktadır. Servis ağı ve markası ise, alım sonrasında oluşabilecek arıza ve teknik sorunların kolaylıkla kısa zamanda çözüme ulaştırılabilmesi ile işin sürekliliğinin sağlanabilmesi için kriterler arasına alınmıştır.

Bu kriterler kendi içinde Tablo 1'de görüldüğü gibi iç ve dış faktörler olmak üzere iki gruba ayrılmaktadır. Kriter sayısının çok olduğu durumlarda işlem kolaylığı sağlaması açısından kriterler kendi içinde gruplara ayrılır. Bu çalışmada Tablo 1'de görüldüğü gibi kriterler iç ve dış faktörler olmak üzere iki gruba ayrılmıştır. İç faktörler forklifti oluşturan teknik özellikler olarak belirlenmiş, forklift seçiminde etkili olabilecek kriterlerden teknik özellikleri dışında kalanlar ise dış faktörler olarak belirlenmiştir.

Tablo 1: Alternatif Değerlendirme Faktörleri

\begin{tabular}{ll}
\hline \multicolumn{2}{l}{ İç Faktörler } \\
\hline $\mathbf{x}_{\mathbf{1}}$ & Dış Dönüş Yarıçapı (mm) \\
$\mathbf{x}_{\mathbf{2}}$ & Asansör Yüksekliği (mm) \\
$\mathbf{x}_{\mathbf{3}}$ & Üst Koruyucu Yüksekliği (mm) \\
\hline Dış Faktörler \\
\hline $\mathbf{y}_{\mathbf{1}}$ & Birim Fiyat (TL) \\
$\mathbf{y}_{\mathbf{2}}$ & Marka Güvenirliği \\
$\mathbf{y}_{\mathbf{3}}$ & Servis Ağı \\
$\mathbf{y}_{\mathbf{4}}$ & Garanti Süresi (Çalışma Saati) \\
\hline
\end{tabular}

İç faktörler $X=\left(x_{1}, x_{2}, x_{3}\right)$ şeklinde gösterilmektedir. $x_{1}$-Dış dönüş yarıçapı $(\mathrm{mm})$, depo içinde forkliftin hareket alanı için ayrılması gereken mesafe açısından önemlidir. Forkliftin depoda raflar arasında hareketi için ayrılması gereken mesafe ne kadar az olursa deponun aktif kullanım alanı daha fazla olur. $x_{2^{-}}$Asansör yüksekliği $(\mathrm{mm})$, forklift ile yüksek seviyedeki raflara ulaşmak ve deponun kullanım alanını artırmak için raf sayısı artırıldığında yeterli olabilmesi açısından önemlidir. $x_{3}$-Üst koruyucu yüksekliği $(\mathrm{mm})$, forkliftin kabinin üst 
seviyesidir. Forklift kullanıcısının görüş açısı, oluşabilecek kazalara karşı korunması ve kabin içinde kullanım rahatlı̆̆ı açısından ne kadar yüksek olursa o kadar iyidir.

Dış faktörler $Y=\left(y_{1}, y_{2}, y_{3}, y_{4}\right)$ şeklinde gösterilmektedir. $y_{1}$ - Birim fiyat1 (TL) alım sürecinde işletmenin sermayesini aktif ve en uygun şekilde kullanması açısından fiyatın düşük olması işletme açısından daha avantajlıdır. $y_{2^{-}}$Marka güvenirliği forklifti alırken verilen sermayenin değer olarak karşılanması, kullanım sürecinde karşılaşılabilecek sorunlarda satın alınan markanın ürününün sıkıntılarını giderebilecek kalite ve güvenilirlikte olması amaçlanır. $y_{3}$-Servis ağ1 forkliftin teknik desteğini gösterdiğinden güvenilirlik açısından önemli bir kriterdir. Ayrıca, forklift çalışma sürecinde oluşabilecek arıza durumlarında sıkıntının bir an önce giderilip forkliftin kısa sürede tekrar kullanılabilmesi için de gereklidir. $y_{4}$ - Garanti süresi, forkliftin kullanım süresi olarak üretici firma ne kadar uzun süre, parça ve tamir garantisi verirse, hem sağlamlık açısından hem de tamir giderlerinin dolaylı olarak düşük olmasını sağlayacă̆ından önemlidir.

Forklift alımında dikkate alınacak kriterler belirlendikten sonra alanında uzman kişiler tarafindan kriterlerin öncelik sıralaması yapılmıştır. Bu çalışmada tekstil işletmesinde çalışan 5 uzmanın görüşü alınmıştır. Görüşlere göre öncelik sıralaması Tablo 2'de gösterilmiştir. Tablo 2 'de 1 ile gösterilen değerler öncelik olarak önem sırasına göre üst seviyede yer alırken sayılar arttıkça önem sırası da azalmaktadır.

Tablo 2: Beş Uzman Grup Tarafından Belirlenen Kriterlerin Öncelik Sıralaması

\begin{tabular}{cccccccc}
\hline $\begin{array}{c}\text { Uzman } \\
\text { Grup }\end{array}$ & $\mathbf{x}_{\mathbf{1}}$ & $\mathbf{x}_{\mathbf{2}}$ & $\mathbf{x}_{\mathbf{3}}$ & $\mathbf{y}_{\mathbf{1}}$ & $\mathbf{y}_{\mathbf{2}}$ & $\mathbf{y}_{\mathbf{3}}$ & $\mathbf{y}_{\mathbf{4}}$ \\
\hline $\mathbf{1}$ & 2 & 3 & 1 & 4 & 1 & 2 & 3 \\
$\mathbf{2}$ & 1 & 2 & 3 & 4 & 3 & 1 & 2 \\
$\mathbf{3}$ & 2 & 1 & 3 & 4 & 3 & 2 & 1 \\
$\mathbf{4}$ & 2 & 1 & 3 & 4 & 1 & 3 & 2 \\
$\mathbf{5}$ & 1 & 2 & 3 & 4 & 3 & 2 & 1 \\
\hline
\end{tabular}

Tablo 2'de uzmanlar tarafından belirlenen kriterlerin önceliklerin sıralaması aşağıda gösterilmiştir.

$$
\begin{array}{lll}
\left(U_{1}\right) & y_{2}>y_{3}>y_{4}>y_{1} & x_{3}>x_{1}>x_{2} \\
\left(U_{2}\right) & y_{3}>y_{4}>y_{2}>y_{1} & x_{1}>x_{2}>x_{3} \\
\left(U_{3}\right) & y_{4}>y_{3}>y_{2}>y_{1} & x_{2}>x_{1}>x_{3} \\
\left(U_{4}\right) & y_{2}>y_{4}>y_{3}>y_{1} & x_{2}>x_{1}>x_{3} \\
\left(U_{5}\right) & y_{4}>y_{3}>y_{2}>y_{1} & x_{1}>x_{2}>x_{3}
\end{array}
$$

Tablo 3'te çalışmada kullanılan forklift alternatiflerinin 7 kriter için karar matrisi oluşturulmuştur. Alternatifler depolamada yaygın şekilde kullanılan forklift markalarından seçilmiştir. Bu markaların, işletmenin kapalı deposunda kullanıma uygun akülü çalışma sistemine sahip, 3 ton kaldırma kapasiteli modelleri seçilmiştir. Belirlenmiş olan kriterler üzerinden markaların yetkili satış mağazalardan kriterlere uygun modelin 2016 yılı Nisan ayı için $y_{1}$-birim fiyatları öğrenilmiştir. $y_{2}-$ marka güvenirliği kriteri için alternatif değerleri uzmanların markaları 1-10 aralığında (10-en iyi performans, 1-en kötü performans) puanlayarak değerlendirmeleri sonucunda oluşturulmuştur. $y_{3}$ - servis ağı kriteri için alternatif değerleri, markaların Ege Bölgesi'nde bulunan toplam bayi sayılarını göstermektedir. Diğer dış kriter verilerinin bilgileri de aynı şekilde yetkili satıcılardan alınmıştır. Markaların teknik özelliklerinin bulunduğu listelerden iç kriter verileri elde edilmiştir. Bu veriler doğrultusunda Tablo 3 'te görüldüğü gibi karar matrisi oluşturulmuştur. 
Tablo 3: Başlangıç Karar Matrisi

\begin{tabular}{c|ccccccc}
\hline \multirow{2}{*}{ Alternatifler } & \multicolumn{1}{|c}{ Kriterler } \\
\cline { 2 - 8 } & $\mathbf{x}_{\mathbf{1}}$ & $\mathbf{x}_{\mathbf{2}}$ & $\mathbf{x}_{\mathbf{3}}$ & $\mathbf{y}_{\mathbf{1}}$ & $\mathbf{y}_{\mathbf{2}}$ & $\mathbf{y}_{\mathbf{3}}$ & $\mathbf{y}_{\mathbf{4}}$ \\
\hline $\mathbf{A}_{\mathbf{1}}$ & 2245 & 3000 & 2170 & 70.146 & 6 & 2 & 2000 \\
$\mathbf{A}_{\mathbf{2}}$ & 2380 & 3487 & 2015 & 118.523 & 2 & 1 & 6000 \\
$\mathbf{A}_{\mathbf{3}}$ & 2140 & 3300 & 2190 & 92.982 & 4 & 1 & 2000 \\
$\mathbf{A}_{\mathbf{4}}$ & 2160 & 3300 & 2215 & 100.918 & 5 & 1 & 6000 \\
$\mathbf{A}_{\mathbf{5}}$ & 2280 & 3000 & 2150 & 68.362 & 1 & 3 & 2500 \\
$\mathbf{A}_{\mathbf{6}}$ & 2300 & 3000 & 2230 & 97.518 & 8 & 4 & 3000 \\
$\mathbf{A}_{\mathbf{7}}$ & 2230 & 3500 & 2110 & 75.510 & 10 & 7 & 2400 \\
$\mathbf{A}_{\mathbf{8}}$ & 2140 & 3000 & 2190 & 66.876 & 3 & 1 & 2000 \\
$\mathbf{A}_{\mathbf{9}}$ & 2087 & 3195 & 2480 & 106.838 & 9 & 5 & 3000 \\
$\mathbf{A}_{\mathbf{1 0}}$ & 1973 & 3826 & 2080 & 82.049 & 7 & 2 & 4000 \\
\hline
\end{tabular}

Bazı kriterlerin değerlerinin yüksek olması işletme açısından istenmeyen bir durum teşkil eder. $\mathrm{Bu}$ minimizasyon kriterlerinin değerleri, $\left(1 / x_{j}^{(i)}, 1 / y_{j^{\prime}}^{(i)}\right)$ şeklinde ifade edilerek uygun veriler halinde çalışmada kullanılmıştır. $\mathrm{Bu}$ çalışmada, $x_{1}$-dış dönüş yarıçapı $(\mathrm{mm})$ ve $y_{1^{-}}$ birim fiyatı (TL) değerlerinin yüksek olması işletme açısından istenmeyen durum oluşturduğundan, bu değerler $\left(1 / x_{j}^{(i)}, 1 / y_{j^{\prime}}^{(i)}\right)$ şeklinde ifade edilerek Tablo 4 oluşturulmuştur.

Daha sonra, Tablo 4'teki veriler kullanılarak 10 alternatif için, Eşitlik (3) yardımıyla kriter değerlerinin normalizayonu yapılmış ve Tablo 5 elde edilmiştir. Normalize edilmiş kriter değerleri $[0 ; 1]$ aralığında yer almalıdır.

Tablo 4: Kriterlerin Maksimizasyon ve Minimizasyon Durumuna Göre Düzenlenmiş

\section{Veriler}

\begin{tabular}{c|ccccccc}
\hline \multirow{2}{*}{ Alternatifler } & \multicolumn{9}{|c}{ Kriterler } \\
\cline { 2 - 8 } & $\mathrm{x}_{1}$ & $\mathrm{x}_{2}$ & $\mathrm{x}_{3}$ & $\mathrm{y}_{1}$ & $\mathrm{y}_{2}$ & $\mathrm{y}_{3}$ & $\mathrm{y}_{4}$ \\
\hline $\mathbf{A}_{\mathbf{1}}$ & 0,000445 & 3000 & 2170 & 0,000014 & 6 & 2 & 2000 \\
$\mathbf{A}_{\mathbf{2}}$ & 0,000420 & 3487 & 2015 & 0,000008 & 2 & 1 & 6000 \\
$\mathbf{A}_{\mathbf{3}}$ & 0,000467 & 3300 & 2190 & 0,000011 & 4 & 1 & 2000 \\
$\mathbf{A}_{\mathbf{4}}$ & 0,000463 & 3300 & 2215 & 0,000010 & 5 & 1 & 6000 \\
$\mathbf{A}_{\mathbf{5}}$ & 0,000439 & 3000 & 2150 & 0,000015 & 1 & 3 & 2500 \\
$\mathbf{A}_{\mathbf{6}}$ & 0,000435 & 3000 & 2230 & 0,000010 & 8 & 4 & 3000 \\
$\mathbf{A}_{\mathbf{7}}$ & 0,000448 & 3500 & 2110 & 0,000013 & 10 & 7 & 2400 \\
$\mathbf{A}_{\mathbf{8}}$ & 0,000467 & 3000 & 2190 & 0,000015 & 3 & 1 & 2000 \\
$\mathbf{A}_{9}$ & 0,000479 & 3195 & 2480 & 0,000009 & 9 & 5 & 3000 \\
$\mathbf{A}_{\mathbf{1 0}}$ & 0,000507 & 3826 & 2080 & 0,000012 & 7 & 2 & 4000 \\
\hline
\end{tabular}


Tablo 5: Normalize Edilmiş Karar Matrisi

\begin{tabular}{cccccccc}
\hline & \multicolumn{7}{c}{ Kriterler } \\
\cline { 2 - 8 } Alternatifler & $\mathbf{x}_{\mathbf{1}}^{*}$ & $\mathbf{x}_{\mathbf{2}}^{*}$ & $\mathbf{x}_{\mathbf{3}}^{*}$ & $\mathbf{y}_{\mathbf{1}}^{*}$ & $\mathbf{y}_{\mathbf{2}}^{*}$ & $\mathbf{y}_{\mathbf{3}}^{*}$ & $\mathbf{y}_{\mathbf{4}}^{*}$ \\
\hline $\mathbf{A}_{\mathbf{1}}$ & 0,292 & 0,000 & 0,333 & 0,893 & 0,556 & 0,167 & 0,000 \\
$\mathbf{A}_{\mathbf{2}}$ & 0,000 & 0,590 & 0,000 & 0,000 & 0,111 & 0,000 & 1,000 \\
$\mathbf{A}_{\mathbf{3}}$ & 0,544 & 0,363 & 0,376 & 0,356 & 0,333 & 0,000 & 0,000 \\
$\mathbf{A}_{\mathbf{4}}$ & 0,494 & 0,363 & 0,430 & 0,226 & 0,444 & 0,000 & 1,000 \\
$\mathbf{A}_{\mathbf{5}}$ & 0,213 & 0,000 & 0,290 & 0,950 & 0,000 & 0,333 & 0,125 \\
$\mathbf{A}_{\mathbf{6}}$ & 0,169 & 0,000 & 0,462 & 0,279 & 0,778 & 0,500 & 0,250 \\
$\mathbf{A}_{\mathbf{7}}$ & 0,326 & 0,605 & 0,204 & 0,738 & 1,000 & 1,000 & 0,100 \\
$\mathbf{A}_{\mathbf{8}}$ & 0,544 & 0,000 & 0,376 & 1,000 & 0,222 & 0,000 & 0,000 \\
$\mathbf{A}_{\mathbf{9}}$ & 0,681 & 0,236 & 1,000 & 0,142 & 0,889 & 0,667 & 0,250 \\
$\mathbf{A}_{\mathbf{1 0}}$ & 1,000 & 1,000 & 0,140 & 0,576 & 0,667 & 0,167 & 0,500 \\
\hline
\end{tabular}

\subsection{Kemeny Medyan Yöntemi ile Kriter Önceliklerinin Belirlenmesi}

KEMIRA yöntemi, Eşitlik (12)'de verilen uzman görüşlerinden kriterlerin öncelik sırasını belirlemek için Kemeny Medyan Yöntemi ile kriterlerin medyanını bulmaya dayanır. İç faktör $X=\left(x_{1}, x_{2}, x_{3}\right)$ kriterleri 3 tane olduğundan medyan 3!=6 olası seçenek arasından seçilir. Benzer şekilde diş faktör $Y=\left(y_{1}, y_{2}, y_{3}, y_{4}\right)$ kriterleri de 4 tane olduğundan medyanı $4 !=24$ olas1 seçenek arasından seçilir. Daha sonra elde edilen medyan temel alınarak Eşitlik (13)'te gösterildiği gibi her kriter değeri için ağırlıklı ortalama hesaplanır.

$$
\begin{array}{ll}
X_{w_{x}}=w_{x_{1}} x_{1}^{*}+w_{x_{2}} x_{2}^{*}+w_{x_{3}} x_{3}^{*} \quad, & w_{x}=\left(w_{x_{1}}, w_{x_{2}}, w_{x_{3}}\right) \\
Y_{w_{y}}=w_{y_{1}} y_{1}^{*}+w_{y_{2}} y_{2}^{*}+w_{y_{3}} y_{3}^{*}+w_{y_{4}} y_{4}^{*}, & w_{y}=\left(w_{y_{1}}, w_{y_{2}}, w_{y_{3}}, w_{y_{4}}\right)
\end{array}
$$

Örneğin, medyan önceliği $y_{2}>y_{3}>y_{4}>y_{1}$ şeklinde sıralansın. Bu durumda ağıllıkları da kriter öncelik sırasına göre aşağıdaki gibi oluşturulur.

$$
w_{y_{2}} \geq w_{y_{3}} \geq w_{y_{4}} \geq w_{y_{1}}, w_{y_{2}}+w_{y_{3}}+w_{y_{4}}+w_{y_{1}}=1
$$

\subsubsection{Y Faktörü için Medyan Belirleme}

KEMIRA yöntemine göre; ilk aşamada, kriterlerin önceliklerinin belirlenmesi amaciyla Kemeny Medyan yöntemi uygulanır. Bunun için Tablo 2'deki verilerden yararlanılır. Bu tabloda yer alan iç ve dış faktörlerin kendi aralarında kriter öncelikleri belirlenir. $X$ kriterinin önceliği $X=\left(x_{1}, x_{2}, x_{3}\right)$ ve $Y$ kriterinin önceliği $Y=\left(y_{1}, y_{2}, y_{3}, y_{4}\right), 5$ uzman tarafindan belirlenir. Uzmanlar kendi görüşleri doğrultusunda kriterlerin öncelik sıralamasını belirlemişlerdir.

Tablo 2'de verilen beş uzman görüşünün her biri basit yönlü bir diyagram ile gösterilebilir (Krylovas, 2016:58). Örneğin birinci uzmanın görüş sırlaması $y_{2}>y_{3}>y_{4}>y_{1}$ Şekil 1 'de gösterilen $R^{(1)}=\{(2 ; 1),(2 ; 3),(2 ; 4),(3 ; 4),(3 ; 1),(4 ; 1)\}$ diyagramı tarafindan elde edilir. 


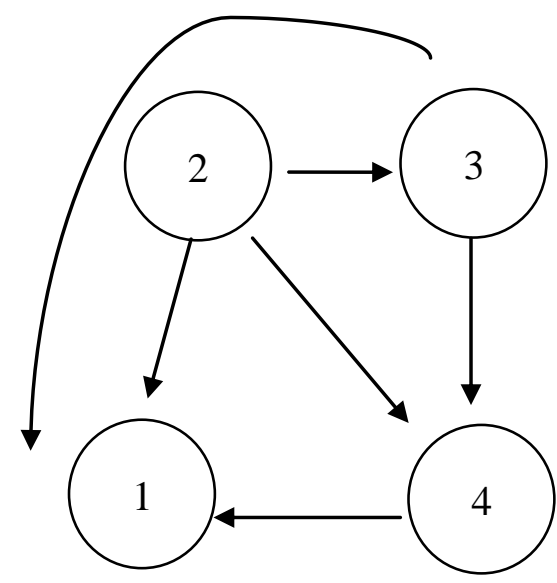

Şekil 1: Birinci uzman tarafindan $y_{2}>y_{3}>y_{4}>y_{1}$ şeklinde yapılan $Y$ kriteri öncelik sıralamasını gösteren basit yönlü diyagram

Şekil 1'de oluşturulan diyagram $a_{j^{\prime} k}=\left\{\begin{array}{ll}0, & \text { ĕger } y_{j^{\prime}}<y_{k} \\ 1, & \text { e ger } y_{j^{\prime}}>y_{k}\end{array} \quad r=1,2, \ldots, 5\right.$ şeklinde olan $A^{(r)}=\left(a_{j^{\prime} k}\right)_{4 \times 4}$ kare matris şeklinde de yazılabilir. Bu matrisin köşegen elemanları sıfıra eşittir. $y_{j^{\prime} j^{\prime}}=0, j^{\prime}=1,2,3,4$. Ayrica $a_{j^{\prime} k}=1-a_{k j^{\prime}}, j^{\prime} \neq k^{\prime}$ dır.

Örneğin; birinci uzman $\left(U_{1}\right)$ tarafindan oluşturulan $y_{1}-y_{4}$ kriterlerinin önceliği $A_{y}^{(1)}=\left(\begin{array}{llll}0 & 0 & 0 & 0 \\ 1 & 0 & 1 & 1 \\ 1 & 0 & 0 & 1 \\ 1 & 0 & 0 & 0\end{array}\right)$ şeklinde bulunur. belirtilmiştir.

Benzer şekilde diğer uzmanlar tarafindan oluşturulan kriter önceliği matrisleri de aşağıda $A_{y}^{(2)}=\left(\begin{array}{llll}0 & 0 & 0 & 0 \\ 1 & 0 & 0 & 0 \\ 1 & 1 & 0 & 1 \\ 1 & 1 & 0 & 0\end{array}\right)$ $A_{y}^{(3)}=A_{y}^{(5)}=\left(\begin{array}{llll}0 & 0 & 0 & 0 \\ 1 & 0 & 0 & 0 \\ 1 & 1 & 0 & 0 \\ 1 & 1 & 1 & 0\end{array}\right)$ $A_{y}^{(4)}=\left(\begin{array}{llll}0 & 0 & 0 & 0 \\ 1 & 0 & 1 & 1 \\ 1 & 0 & 0 & 0 \\ 1 & 0 & 1 & 0\end{array}\right)$

$A^{(r)}$ ve $A^{(s)}$ matrisleri tarafından tanımlanan iki farklı sıralama arasındaki farkın ölçümü Eşitlik (5) kullanılarak elde edilir. Eşitlik (5)'te gösterilen $n$ değeri $y_{1}, y_{2}, \ldots, y_{n}$ kriterlerin sayısını ifade etmektedir. Çalışmada $Y$ kriterlerinin sayısı 4 olduğundan $n$ değeri 4'e eşittir.

Eşitlik (5) kullanılarak her iki matris için sırayla $m$. satır ve $n$. sütün elemanlarının farkının mutlak değeri hesaplanır (1. satır - 1. sütün, 1. satır - 2. Sütün, $\ldots, m$. satır $-n$. sütün elemanları arasındaki farkın mutlak değeri).

Örneğin;

$$
\begin{aligned}
\rho\left(A^{(1)}, A^{(2)}\right)= & |0-0|+|0-0|+|0-0|+|0-0|+|1-1|+|0-0|+|1-0|+ \\
& |1-0|+|1-1|+|0-1|+|0-0|+|1-1|+|1-1|+|0-1|+ \\
& |0-0|+|0-0|=4
\end{aligned}
$$

elde edilir. 
Beş uzman tarafından tanımlanan $A^{(1)}, A^{(2)}, \ldots, A^{(5)}$ öncelik matrisleri oluşturulsun. Bu çalışmada $n=4$ olduğundan medyan $A^{(M)}=\left\|a_{j^{\prime} k}\right\|_{4 x 4}$ matrisi $4 !=24$ olası matris içinden araştırılır. Fakat bu 24 olası seçeneği incelemek çok zaman alacağı için arama alanı daraltılmaya çalışılır. Eğer 5 matrisin $j^{\prime}$ ve $k$ indislerine sahip tüm elemanları eşit ise,

$a_{j^{\prime} k}^{(M)}=a_{j^{\prime} k}^{(1)}=a_{j^{\prime} k}^{(2)}=\cdots=a_{j^{\prime} k}^{(5)}$ dir.

Bu durumda,

$$
A^{(M)}=\left(\begin{array}{cccc}
0 & 0 & 0 & 0 \\
1 & 0 & a_{23} & a_{24} \\
1 & a_{32} & 0 & a_{34} \\
1 & a_{42} & a_{43} & 0
\end{array}\right)
$$

Eşitlik (15)'de elde edilen medyan matrisinin elemanlarının sadece 3 tanesi bilinmemektedir, çünkü $a_{j^{\prime} k}+a_{k j^{\prime}}=1$ ve $j^{\prime} \neq k$ özdeşlikleri basit yönlü diyagram matrisi için geçerlidir (Krylovas, 2016: 57).

Bu yüzden $a_{32}=1-a_{23}, \quad a_{42}=1-a_{24} \quad$ ve $a_{43}=1-a_{34} \quad$ ve $j^{\prime} \neq k \quad$ olma durumunu da göz önünde bulundurarak 8 olası matris içinden medyan araştırılabilir.

Eşitlik (4) kullanılarak 8 olası matrisin öncelik kriter matrisi oluşturulur.

$A^{1}=\left(\begin{array}{llll}0 & 0 & 0 & 0 \\ 1 & 0 & 0 & 0 \\ 1 & 1 & 0 & 0 \\ 1 & 1 & 1 & 0\end{array}\right) \quad A^{2}=\left(\begin{array}{llll}0 & 0 & 0 & 0 \\ 1 & 0 & 1 & 1 \\ 1 & 0 & 0 & 1 \\ 1 & 0 & 0 & 0\end{array}\right) \quad A^{3}=\left(\begin{array}{llll}0 & 0 & 0 & 0 \\ 1 & 0 & 0 & 1 \\ 1 & 1 & 0 & 0 \\ 1 & 0 & 1 & 0\end{array}\right)$

$A^{4}=\left(\begin{array}{llll}0 & 0 & 0 & 0 \\ 1 & 0 & 1 & 1 \\ 1 & 0 & 0 & 0 \\ 1 & 0 & 1 & 0\end{array}\right) \quad A^{5}=\left(\begin{array}{llll}0 & 0 & 0 & 0 \\ 1 & 0 & 0 & 0 \\ 1 & 1 & 0 & 1 \\ 1 & 1 & 0 & 0\end{array}\right) \quad A^{6}=\left(\begin{array}{llll}0 & 0 & 0 & 0 \\ 1 & 0 & 1 & 0 \\ 1 & 0 & 0 & 1 \\ 1 & 1 & 0 & 0\end{array}\right)$

$A^{7}=\left(\begin{array}{llll}0 & 0 & 0 & 0 \\ 1 & 0 & 1 & 0 \\ 1 & 0 & 0 & 0 \\ 1 & 1 & 1 & 0\end{array}\right) \quad A^{8}=\left(\begin{array}{llll}0 & 0 & 0 & 0 \\ 1 & 0 & 0 & 1 \\ 1 & 1 & 0 & 1 \\ 1 & 0 & 0 & 0\end{array}\right)$

Eşitlik (5) kullanılarak,

$$
\begin{array}{ll}
\sum_{s=1}^{5} \rho\left(A^{1}, A^{(s)}\right)=6+2+0+4+0=12 & \sum_{s=1}^{5} \rho\left(A^{2}, A^{(s)}\right)=18 \\
\sum_{s=1}^{5} \rho\left(A^{3}, A^{(s)}\right)=14 & \sum_{s=1}^{5} \rho\left(A^{4}, A^{(s)}\right)=16 \\
\sum_{s=1}^{5} \rho\left(A^{5}, A^{(s)}\right)=14 & \sum_{s=1}^{5} \rho\left(A^{6}, A^{(s)}\right)=16 \\
\sum_{s=1}^{5} \rho\left(A^{7}, A^{(s)}\right)=14 & \sum_{s=1}^{5} \rho\left(A^{8}, A^{(s)}\right)=16
\end{array}
$$


minimum toplam değere $A^{1}$ matrisinde ulaşılır. Bu durumda 5 uzman görüşünün en iyisini temsil eden medyan değeri diş faktörlerin tercihinde belirlenen $U_{3}=U_{5}=(4,3,2,1)$, yani $y_{4}>y_{3}>y_{2}>y_{1}$ 'dir. En yüksek önceliğe garanti süresi sahipken, ikinci sırada servis ağı, üçüncü sırada marka güvenilirliği ve en son sırada ise birim fiyat gelmektedir.

Her bir alternatif için Eşitlik (17)' deki gibi ağırlıklı ortalama değerleri yazılır.

$Y_{w_{y}}(a)=\sum_{j^{\prime}=1}^{4} w_{y_{j^{\prime}}} y_{j^{\prime}}^{*}(a)=w_{y_{1}} y_{1}^{*}(a)+w_{y_{2}} y_{2}^{*}(a)+w_{y_{3}} y_{3}^{*}(a)+w_{y_{4}} y_{4}^{*}(a)$

Burada ağırlıklar,

$$
w_{y_{4}} \geq w_{y_{3}} \geq w_{y_{2}} \geq w_{y_{1}} \geq 0 \quad \text { ve } \quad w_{y_{1}}+w_{y_{2}}+w_{y_{3}}+w_{y_{4}}=1^{\prime} \text { dir. }
$$

\subsubsection{Faktörü için Medyan Belirleme}

KEMIRA yöntemine göre ilk aşamada Kemeny Medyan yöntemi hem iç faktörler hem dış faktörler olmak üzere Tablo 2'de gösterilen kriter öncelikleri için uygulanır. $X=\left(x_{1}, x_{2}, x_{3}\right)$, $Y=\left(y_{1}, y_{2}, y_{3}, y_{4}\right)$ kriterleri Tablo 2 'de görüldüğü gibi beş uzmanın öncelik sirasına göre belirlenmiştir.

$X$ faktörü (iç faktörler) için, beş uzman tarafından oluşturulan kriter öncelik sıralaması Eşitlik (19)'da gösterilmiştir.

$$
\begin{array}{cc}
\left(U_{1}\right) & x_{3}>x_{1}>x_{2} \\
\left(U_{2}\right) & x_{1}>x_{2}>x_{3} \\
\left(U_{3}\right) & x_{2}>x_{1}>x_{3} \\
\left(U_{4}\right) & x_{2}>x_{1}>x_{3} \\
\left(U_{5}\right) & x_{1}>x_{2}>x_{3}
\end{array}
$$

Uzmanların görüşleri doğrultusunda oluşturulan kriter öncelik matrisleri $A^{(r)}=$ $\left(a_{j k}\right)_{3 \times 3}$ Eşitlik (4) kullanılarak elde edilir.

$$
A^{(1)}=\left(\begin{array}{lll}
0 & 1 & 0 \\
0 & 0 & 0 \\
1 & 1 & 0
\end{array}\right)_{3 \times 3} \quad A^{(2)}=A^{(5)}\left(\begin{array}{lll}
0 & 1 & 1 \\
0 & 0 & 1 \\
0 & 0 & 0
\end{array}\right)_{3 \times 3} \quad A^{(3)}=A^{(4)}=\left(\begin{array}{lll}
0 & 0 & 1 \\
1 & 0 & 1 \\
0 & 0 & 0
\end{array}\right)_{3 \times 3}
$$

Çalışmada $m=3$ olduğundan medyan $A^{(M)}=\left\|a_{j k}\right\|_{3 \times 3}$ matrisi $3 !=6$ olası matris içinden araştırılmalıdır. 
Tablo 6: 6 Olası Seçenek İçin Öncelik Matrislerinin Oluşturulması ve $F$ Fonksiyon Değerinin Bulunması

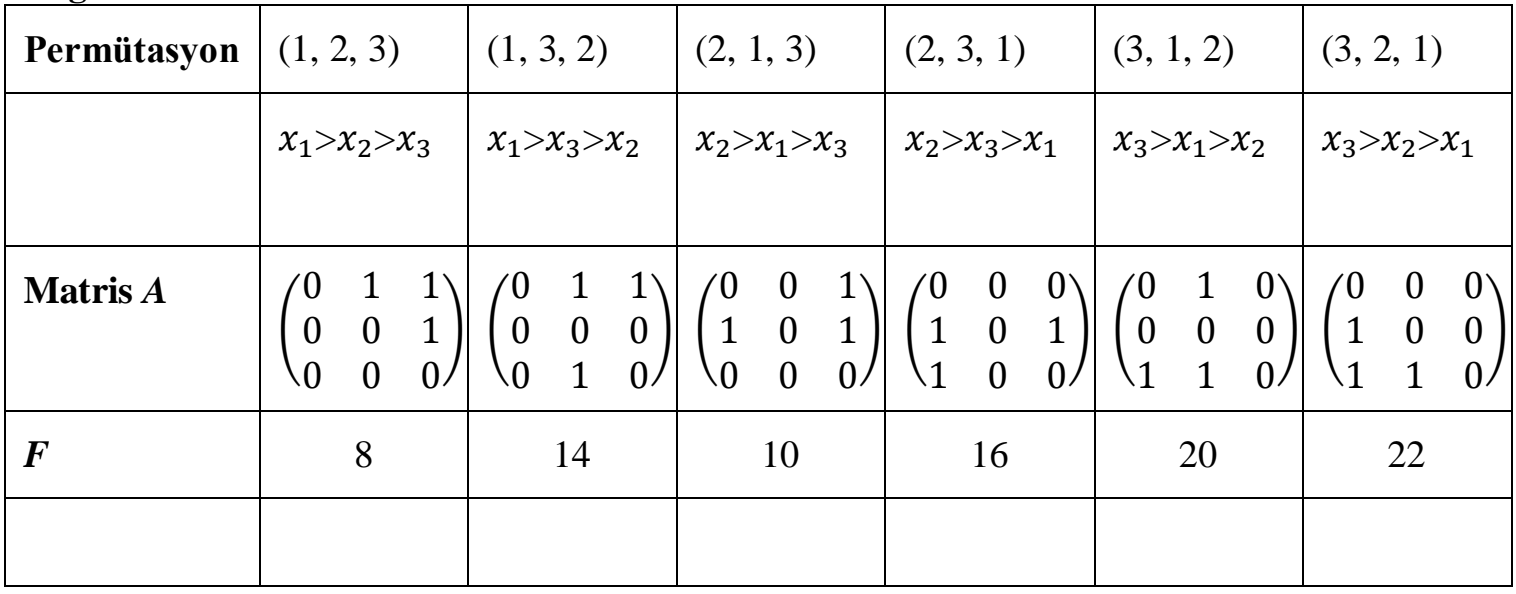

$$
\begin{array}{ccc}
A_{x}^{(1)}=\left(\begin{array}{lll}
0 & 1 & 0 \\
0 & 0 & 0 \\
1 & 1 & 0
\end{array}\right) & A_{x}^{(2)}=A_{x}^{(5)}\left(\begin{array}{lll}
0 & 1 & 1 \\
0 & 0 & 1 \\
0 & 0 & 0
\end{array}\right) & A_{x}^{(3)}=A_{x}^{(4)}=\left(\begin{array}{lll}
0 & 0 & 1 \\
1 & 0 & 1 \\
0 & 0 & 0
\end{array}\right) \\
A_{x}^{(6)}=\left(\begin{array}{lll}
0 & 1 & 1 \\
0 & 0 & 0 \\
0 & 1 & 0
\end{array}\right) & A_{x}^{(7)}=\left(\begin{array}{lll}
0 & 0 & 0 \\
1 & 0 & 1 \\
1 & 0 & 0
\end{array}\right) & A_{x}^{(8)}=\left(\begin{array}{lll}
0 & 0 & 0 \\
1 & 0 & 0 \\
1 & 1 & 0
\end{array}\right)
\end{array}
$$

$A^{(r)}$ ve $A^{(s)}$ matrisleri tarafindan tanımlanan iki farklı sıralama arasındaki farkın ölçümü Eşitlik (5) kullanılarak elde edilir. Bu eşitlikte gösterilen $m$ değeri $x_{1}, x, \ldots, x_{m}$ kriterlerin sayısını ifade etmektedir. Çalışmada $X$ kriterlerinin sayısı 3 olduğundan $m$ değeri 3'e eşittir.

Beş uzman tarafindan tanımlanabilen $A^{(1)}, A^{(2)}, \ldots, A^{(5)}$ öncelik matrisleri oluşturulur. Çalışmada $m=3$ olduğundan medyan $A^{(M)}=\left\|a_{j k}\right\|_{3 \times 3}$ matrisi $3 !=6$ olası matris içinden araştırılır. Tablo 6' da, 6 olası durumun kriter öncelik matrisleri arasından $A^{(M)}$ medyan matrisini bulmak için Eşitlik (5) kullanılır.

$$
\begin{aligned}
& \sum_{s=1}^{5} \rho\left(A^{(1)}, A^{(s)}\right)=0+4+6+6+4=20 \\
& \sum_{s=1}^{5} \rho\left(A^{(3)}, A^{(s)}\right)=6+2+0+0+2=10 \\
& \sum_{s=1}^{5} \rho\left(A^{(5)}, A^{(s)}\right)=4+0+2+2+0=8 \\
& \sum_{s=1}^{5} \rho\left(A^{(7)}, A^{(s)}\right)=4+4+2+2+4=16
\end{aligned}
$$$$
\sum_{s=1}^{5} \rho\left(A^{(2)}, A^{(s)}\right)=4+0+2+2+0=8
$$$$
\sum_{s=1}^{5} \rho\left(A^{(4)}, A^{(s)}\right)=6+2+0+0+2=10
$$$$
\sum_{s=1}^{5} \rho\left(A^{(6)}, A^{(s)}\right)=2+2+4+4+2=14
$$$$
\sum_{s=1}^{5} \rho\left(A^{(8)}, A^{(s)}\right)=2+6+4+4+6=22
$$

Minimum toplam değere $A^{(2)} \mathrm{ve} A^{(5)}$ matrisinde ulaşılmıştır. Bu durumda 5 uzman görüşünün en iyisini temsil eden medyan değeri iç faktörlerin tercihinde belirlenen $U_{2}=U_{5}=$ $(1,2,3)$ veya $x_{1}>x_{2}>x_{3}$ şeklinde elde edilir.

En yüksek önceliğe dış dönüş yarıçapı sahipken onu sırasıyla, asansör yüksekliği ve üst koruyucu yüksekliği oluşturmaktadır. Her bir alternatif için Eşitlik (20)'deki gibi ağırlıklı ortalama değerleri yazılır.

$$
X_{w_{x}}(a)=\sum_{j=1}^{3} w_{x_{j}} x_{j}^{*}(a)=w_{x_{1}} x_{1}^{*}(a)+w_{x_{2}} x_{2}^{*}(a)+w_{x_{3}} x_{3}^{*}(a)
$$


Burada ağırlıklar $w_{x_{1}}, w_{x_{2}}, w_{x_{3}}$

$$
w_{x_{1}} \geq w_{x_{2}} \geq w_{x_{3}} \geq 0 \text { ve } w_{x_{1}}+w_{x_{2}}+w_{x_{3}}=1 \text { şartlarını sağlar. }
$$

\subsection{Modifiye Edilmiş Sıralama Uygunluk Göstergesi (Indicator Rank Accordance) Yöntemi ile Ağırlıkların Hesaplanması ve Alternatiflerin Sıralanması}

Kriter öncelikleri belirlendikten sonra, Siralama Uygunluk Göstergesi yöntemiyle kriterlerin ağırlıkları belirlenir. Eşitlik (18) ve Eşitlik (21)'de belirtilen koşulları sağlayan $w_{x_{j}}, w_{y_{j^{\prime}}} \in[0 ; 1]$ ağırlıklı katsayıları bulunur. Tablo 7 ve Tablo 8'de $w_{x_{j}}$ ve $w_{y_{j^{\prime}}}$ 'nin olas1 ağırlıklı katsayı değerleri gösterilmiştir. Tablo 7'de görüldüğ̈̈ gibi, $w_{y_{1}}+w_{y_{2}}+w_{y_{3}}+w_{y_{4}}=$ 1 ve $w_{y_{4}} \geq w_{y_{3}} \geq w_{y_{2}} \geq w_{y_{1}} \geq 0$ koşullarını sağlayacak şekilde kriter ağırlıklarının tablosu oluşturulur. Burada en önemli kriterin alacağı en büyük ağırlık değeri 1 olmak zorundadır. Tablo 7 oluşturulurken kriterlerin ağırlık sıralaması ve ağırlıklarının toplamı 1'e eşit olma kuralı dikkate alınarak $w_{y_{j^{\prime}}}$ ağırlıklarının olası durumları elde edilir. $w_{y_{j^{\prime}}} \in[0 ; 1] \quad$ kriterinin ağırlıklarının katsayısının $0 \leq w_{y_{j^{\prime}}} \leq 1$ aralığında olduğuna da dikkat edilmelidir. Benzer şekilde Tablo 8 de Tablo 7 gibi elde edilir.

Tablo 7: $\quad w_{y_{4}} \geq w_{y_{3}} \geq w_{y_{2}} \geq w_{y_{1}} \geq 0$ Koşulunu Sağlayan $w_{y_{j^{\prime}}}$ Ağırlıklarının Olası Durumları

\begin{tabular}{|c|c|c|c|c|c|c|c|c|c|}
\hline No & $\boldsymbol{w}_{\boldsymbol{y}_{\mathbf{1}}}$ & $\boldsymbol{w}_{\boldsymbol{y}_{\mathbf{2}}}$ & $\boldsymbol{w}_{\boldsymbol{y}_{\boldsymbol{3}}}$ & $\boldsymbol{w}_{\boldsymbol{y}_{\mathbf{4}}}$ & $\mathbf{N o}$ & $\boldsymbol{w}_{\boldsymbol{y}_{\mathbf{1}}}$ & $\boldsymbol{w}_{\boldsymbol{y}_{\mathbf{2}}}$ & $\boldsymbol{w}_{\boldsymbol{y}_{\boldsymbol{3}}}$ & $\boldsymbol{w}_{\boldsymbol{y}_{\boldsymbol{4}}}$ \\
\hline $\mathbf{1}$ & 0 & 0 & 0 & 1 & $\mathbf{1 3}$ & 0 & 0,1 & 0,4 & 0,5 \\
\hline $\mathbf{2}$ & 0 & 0 & 0,1 & 0,9 & $\mathbf{1 4}$ & 0 & 0,2 & 0,3 & 0,5 \\
\hline $\mathbf{3}$ & 0 & 0 & 0,2 & 0,8 & $\mathbf{1 5}$ & 0,1 & 0,1 & 0,3 & 0,5 \\
\hline $\mathbf{4}$ & 0 & 0,1 & 0,1 & 0,8 & $\mathbf{1 6}$ & 0,1 & 0,2 & 0,2 & 0,5 \\
\hline $\mathbf{5}$ & 0 & 0 & 0,3 & 0,7 & $\mathbf{1 7}$ & 0 & 0,2 & 0,4 & 0,4 \\
\hline $\mathbf{6}$ & 0 & 0,1 & 0,2 & 0,7 & $\mathbf{1 8}$ & 0,1 & 0,1 & 0,4 & 0,4 \\
\hline $\mathbf{7}$ & 0,1 & 0,1 & 0,1 & 0,7 & $\mathbf{1 9}$ & 0 & 0,3 & 0,3 & 0,4 \\
\hline $\mathbf{8}$ & 0 & 0 & 0,4 & 0,6 & $\mathbf{2 0}$ & 0,1 & 0,2 & 0,3 & 0,4 \\
\hline $\mathbf{9}$ & 0 & 0,1 & 0,3 & 0,6 & $\mathbf{2 1}$ & 0,2 & 0,2 & 0,2 & 0,4 \\
\hline $\mathbf{1 0}$ & 0 & 0,2 & 0,2 & 0,6 & $\mathbf{2 2}$ & 0,1 & 0,3 & 0,3 & 0,3 \\
\hline $\mathbf{1 1}$ & 0,1 & 0,1 & 0,2 & 0,6 & $\mathbf{2 3}$ & 0,2 & 0,2 & 0,3 & 0,3 \\
\hline $\mathbf{1 2}$ & 0 & 0 & 0,5 & 0,5 & & & & & \\
\hline
\end{tabular}

Tablo 8: $w_{x_{1}} \geq w_{x_{2}} \geq w_{x_{3}} \geq 0$ Koşulunu Sağlayan $w_{x_{j}}$ Ağırlıklarının Olası Durumları

\begin{tabular}{|c|c|c|c|c|c|c|c|}
\hline No & $\boldsymbol{w}_{\boldsymbol{x}_{\mathbf{1}}}$ & $\boldsymbol{w}_{\boldsymbol{x}_{\mathbf{2}}}$ & $\boldsymbol{w}_{\boldsymbol{x}_{\mathbf{3}}}$ & $\mathbf{N o}$ & $\boldsymbol{w}_{\boldsymbol{x}_{\mathbf{1}}}$ & $\boldsymbol{w}_{\boldsymbol{x}_{\mathbf{2}}}$ & $\boldsymbol{w}_{\boldsymbol{x}_{\mathbf{3}}}$ \\
\hline $\mathbf{1}$ & 1 & 0 & 0 & $\mathbf{8}$ & 0,6 & 0,3 & 0,1 \\
\hline $\mathbf{2}$ & 0,9 & 0,1 & 0 & $\mathbf{9}$ & 0,6 & 0,2 & 0,2 \\
\hline $\mathbf{3}$ & 0,8 & 0,2 & 0 & $\mathbf{1 0}$ & 0,5 & 0,5 & 0 \\
\hline $\mathbf{4}$ & 0,8 & 0,1 & 0,1 & $\mathbf{1 1}$ & 0,5 & 0,4 & 0,1 \\
\hline $\mathbf{5}$ & 0,7 & 0,3 & 0 & $\mathbf{1 2}$ & 0,5 & 0,3 & 0,2 \\
\hline $\mathbf{6}$ & 0,7 & 0,2 & 0,1 & $\mathbf{1 3}$ & 0,4 & 0,4 & 0,2 \\
\hline $\mathbf{7}$ & 0,6 & 0,4 & 0 & $\mathbf{1 4}$ & 0,4 & 0,3 & 0,3 \\
\hline
\end{tabular}


Eşitlik (11) kullanılarak tüm olası ağırlıklar için $F(X, Y)$ fonksiyon değerleri hesaplanır ve Tablo 9 oluşturulur. Bu değerlerin en küçüğü dikkate alınır. Tablo 9 oluşturulurken Tablo 5 'teki normalize edilmiş karar matrisinden ve $w_{x_{j}}, w_{y_{j^{\prime}}}$ ağırlıklarının olası durumlarının verildiği Tablo 7 ve Tablo 8'den yararlanılır. Örneğin Tablo 9'daki $F(1,1)$ 'in elde edilişi gösterilecek olursa;

$$
\begin{aligned}
& X_{W_{x}}(a)=\sum_{j=1}^{m} w_{x_{j}} x_{j}^{*}(a) \\
& X_{w_{1}}(1)=(1 * 0,292)+(0 * 0)+(0 * 0,333)=0,292 \\
& X_{w_{1}}(2)=(1 * 0)+(0 * 0,590)+(0 * 0)=0 \\
& X_{w_{1}}(3)=(1 * 0,544)+(0 * 0,363)+(0 * 0,376)=0,544 \\
& X_{w_{1}}(4)=(1 * 0,494)+(0 * 0,363)+(0 * 0,430)=0,494 \\
& X_{w_{1}}(5)=(1 * 0,213)+(0 * 0)+(0 * 0,290)=0,213 \\
& X_{w_{1}}(6)=(1 * 0,169)+(0 * 0)+(0 * 0,462)=0,169 \\
& X_{w_{1}}(7)=(1 * 0,326)+(0 * 0,605)+(0 * 0,204)=0,326 \\
& X_{w_{1}}(8)=(1 * 0,544)+(0 * 0)+(0 * 0,376)=0,544 \\
& X_{w_{1}}(9)=(1 * 0,681)+(0 * 0,236)+(0 * 1)=0,681 \\
& X_{w_{1}}(10)=(1 * 1)+(0 * 1)+(0 * 0,140)=1 \\
& Y_{W_{y}}(a)=\sum_{j^{\prime}}^{n} w_{y_{j^{\prime}}} y_{j^{\prime}}^{*} \\
& Y_{w_{1}}(1)=(0 * 0,893)+(0 * 0,556)+(0 * 0,167)+(1 * 0)=0 \\
& Y_{w_{1}}(2)=(0 * 0)+(0 * 0,111)+(0 * 0)+(1 * 1)=1 \\
& Y_{w_{1}}(3)=(0 * 0,356)+(0 * 0,333)+(0 * 0)+(1 * 0)=0 \\
& Y_{w_{1}}(4)=(0 * 0,226)+(0 * 0,444)+(0 * 0)+(1 * 1)=1 \\
& Y_{w_{1}}(5)=(0 * 0,950)+(0 * 0)+(0 * 0,333)+(1 * 0,125)=0,125 \\
& Y_{w_{1}}(6)=(0 * 0,279)+(0 * 0,778)+(0 * 0,500)+(1 * 0,250)=0,250 \\
& Y_{w_{1}}(7)=(0 * 0,738)+(0 * 1)+(0 * 1)+(1 * 0,100)=0,100 \\
& Y_{w_{1}}(8)=(0 * 1)+(0 * 0,222)+(0 * 0)+(1 * 0)=0 \\
& Y_{w_{1}}(9)=(0 * 0,142)+(0 * 0,889)+(0 * 0,667)+(1 * 0,250)=0,250 \\
& Y_{w_{1}}(10)=(0 * 0,576)+(0 * 0,667)+(0 * 0,167)+(1 * 0,500)=0,500 \\
&
\end{aligned}
$$

$$
\begin{aligned}
\left|X_{w_{1}}(a)-Y_{w_{1}}(a)\right|= & |0,292-0|+|0-1|+|0,544-0|+|0,494-1|+ \\
& |0,213-0,125|+|0,169-0,250|+|0,326-0,100|+ \\
& |0,544-0|+|0,681-0,250|+|1-0,500|=4,211
\end{aligned}
$$


Tablo 9: Tüm Olası Ağırlıklar İçin $F(X, Y)$ Fonksiyonun Değerleri

\begin{tabular}{|c|c|c|c|c|c|c|c|}
\hline & 1 & 2 & 3 & 4 & 5 & 6 & 7 \\
\hline 1 & 4,211 & 4,042 & 3,874 & 3,932 & 3,706 & 3,763 & 3,537 \\
\hline 2 & 3,900 & 3,732 & 3,563 & 3,621 & 3,395 & 3,452 & 3,263 \\
\hline 3 & 3,589 & 3,421 & 3,252 & 3,310 & 3,120 & 3,142 & 2,994 \\
\hline 4 & 3,539 & 3,371 & 3,202 & 3,260 & 3,034 & 3,092 & 2,877 \\
\hline 5 & 3,366 & 3,142 & 2,976 & 3,055 & 2,850 & 2,850 & 2,725 \\
\hline 6 & 3,316 & 3,092 & 2,891 & 3,005 & 2,734 & 2,781 & 2,608 \\
\hline 7 & 3,039 & 2,877 & 2,751 & 2,755 & 2,626 & 2,625 & 2,500 \\
\hline 8 & 3,235 & 3,045 & 2,863 & 2,943 & 2,682 & 2,761 & 2,500 \\
\hline 9 & 3,185 & 2,961 & 2,747 & 2,875 & 2,565 & 2,650 & 2,383 \\
\hline 10 & 3,135 & 2,911 & 2,687 & 2,825 & 2,463 & 2,600 & 2,266 \\
\hline 11 & 2,949 & 2,768 & 2,586 & 2,666 & 2,404 & 2,484 & 2,237 \\
\hline \multirow[t]{2}{*}{12} & 3,138 & 2,956 & 2,774 & 2,854 & 2,592 & 2,672 & 2,411 \\
\hline & 8 & 9 & 10 & 11 & 12 & 13 & 14 \\
\hline 1 & 3,595 & 3,652 & 3,406 & 3,426 & 3,484 & 3,316 & 3,373 \\
\hline 2 & 3,284 & 3,342 & 3,137 & 3,137 & 3,173 & 3,010 & 3,062 \\
\hline 3 & 2,993 & 3,031 & 2,868 & 2,867 & 2,867 & 2,741 & 2,752 \\
\hline 4 & 2,923 & 2,981 & 2,751 & 2,755 & 2,812 & 2,644 & 2,702 \\
\hline 5 & 2,724 & 2,748 & 2,599 & 2,598 & 2,598 & 2,472 & 2,471 \\
\hline 6 & 2,612 & 2,695 & 2,482 & 2,482 & 2,502 & 2,355 & 2,391 \\
\hline 7 & 2,499 & 2,499 & 2,405 & 2,373 & 2,373 & 2,247 & 2,247 \\
\hline 8 & 2,580 & 2,659 & 2,329 & 2,398 & 2,478 & 2,296 & 2,376 \\
\hline 9 & 2,463 & 2,564 & 2,213 & 2,281 & 2,361 & 2,179 & 2,259 \\
\hline 10 & 2,376 & 2,514 & 2,102 & 2,165 & 2,290 & 2,065 & 2,203 \\
\hline 11 & 2,302 & 2,382 & 2,170 & 2,121 & 2,200 & 2,019 & 2,098 \\
\hline \multirow[t]{2}{*}{12} & 2,490 & 2,570 & 2,229 & 2,309 & 2,388 & 2,207 & 2,286 \\
\hline & 1 & 2 & $\mathbf{3}$ & 4 & 5 & 6 & 7 \\
\hline 13 & 3,054 & 2,839 & 2,657 & 2,744 & 2,476 & 2,555 & 2,294 \\
\hline 14 & 3,004 & 2,780 & 2,556 & 2,694 & 2,359 & 2,470 & 2,177 \\
\hline 15 & 2,860 & 2,678 & 2,497 & 2,576 & 2,315 & 2,395 & 2,173 \\
\hline 16 & 2,744 & 2,562 & 2,381 & 2,460 & 2,258 & 2,278 & 2,134 \\
\hline 17 & 2,883 & 2,649 & 2,452 & 2,563 & 2,270 & 2,350 & 2,177 \\
\hline 18 & 2,824 & 2,617 & 2,409 & 2,502 & 2,241 & 2,306 & 2,117 \\
\hline 19 & 2,824 & 2,599 & 2,375 & 2,513 & 2,217 & 2,289 & 2,183 \\
\hline 20 & 2,654 & 2,473 & 2,325 & 2,371 & 2,202 & 2,215 & 2,078 \\
\hline 21 & 2,557 & 2,433 & 2,310 & 2,323 & 2,187 & 2,200 & 2,063 \\
\hline 22 & 2,553 & 2,404 & 2,254 & 2,280 & 2,124 & 2,131 & 2,090 \\
\hline \multirow[t]{2}{*}{23} & 2,620 & 2,471 & 2,321 & 2,348 & 2,172 & 2,198 & 2,022 \\
\hline & 8 & 9 & 10 & 11 & 12 & 13 & 14 \\
\hline 13 & 2,374 & 2,453 & 2,157 & 2,192 & 2,272 & 2,090 & 2,170 \\
\hline 14 & 2,257 & 2,383 & 2,115 & 2,075 & 2,159 & 1,973 & 2,072 \\
\hline 15 & 2,213 & 2,293 & 2,050 & 2,063 & 2,111 & 1,953 & 2,009 \\
\hline 16 & 2,147 & 2,176 & 2,011 & 2,024 & 2,037 & 1,914 & 1,927 \\
\hline 17 & 2,168 & 2,252 & 2,143 & 2,006 & 2,066 & 1,884 & 1,964 \\
\hline 18 & 2,130 & 2,204 & 2,017 & 2,007 & 2,022 & 1,897 & 1,920 \\
\hline 19 & 2,081 & 2,202 & 2,148 & 2,009 & 1,987 & 1,834 & 1,892 \\
\hline 20 & 2,092 & 2,105 & 2,022 & 1,968 & 1,981 & 1,858 & 1,871 \\
\hline 21 & 2,076 & 2,089 & 1,940 & 1,953 & 1,966 & 1,842 & 1,856 \\
\hline 22 & 1,997 & 2,010 & 2,055 & 1,916 & 1,887 & 1,763 & 1,776 \\
\hline 23 & 2,049 & 2,075 & 1,929 & 1,899 & 1,926 & 1,787 & 1,803 \\
\hline
\end{tabular}


Tablo 9'da $F(X, Y)$ fonksiyonun değeri $23 \times 14=322$ durum için hesaplanmıştır. $F(X, Y)$ fonksiyonun en küçük değeri 1,763'tür. En küçük $F$ fonksiyon değeri $Y$ kriteri için 22. satırda, $X$ kriteri için de 13. sütunda elde edilmiştir. $Y$ kriterinin ağırlığını bulmak için Tablo 7'de 22. satırdaki değere, benzer şekilde $X$ kriterinin ağırlığını bulmak için Tablo 8'de 13. satırdaki değere bakılarak $X$ ve $Y$ kriterlerinin ağırlıkları elde edilir. $X=\left(x_{1}, x_{2}, x_{3}\right)$ iç kriterleri için kriter ağırlıkları $w_{x_{1}}=0,4 \quad, \quad w_{x_{2}}=0,4 \quad w_{x_{3}}=0,2 \quad$ şeklinde elde edilmiştir. $Y=\left(y_{1}, y_{2}, y_{3}, y_{4}\right)$ dış kriterleri için de kriter ağırlıkları $w_{y_{1}}=0,1, \quad w_{y_{2}}=0,3, w_{y_{3}}=0,3$ ve $w_{y_{4}}=0,3$ şeklinde elde edilmiştir.

Daha sonra, her bir alternatifin $X_{w_{x}}$ ve $Y_{w_{y}}$ değerleri Eşitlik (10) yardımıyla bulunur ve $X_{w_{x}}+Y_{w_{y}}$ değerleri hesaplandıktan sonra bu değerler büyükten küçüğe siralanarak alternatifler arasındaki sıralama Tablo 10’da görüldüğü gibi belirlenir.

Tablo 10: Alternatiflerin Siralanması

\begin{tabular}{cccccccccccc}
\hline $\boldsymbol{w}_{\boldsymbol{x}}, \boldsymbol{w}_{\boldsymbol{y}}$ & $\mathbf{0 , 4}$ & $\mathbf{0 , 4}$ & $\mathbf{0 , 2}$ & $\mathbf{0 , 1}$ & $\mathbf{0 , 3}$ & $\mathbf{0 , 3}$ & $\mathbf{0 , 3}$ & & & & \\
\hline Alternatifler & $\mathbf{x}_{\mathbf{1}}$ & $\mathbf{x}_{\mathbf{2}}$ & $\mathbf{x}_{\mathbf{3}}$ & $\mathbf{y}_{\mathbf{1}}$ & $\mathbf{y}_{\mathbf{2}}$ & $\mathbf{y}_{\mathbf{3}}$ & $\mathbf{y}_{\mathbf{4}}$ & $\boldsymbol{X}_{\boldsymbol{w}_{\boldsymbol{x}}}$ & $\boldsymbol{Y}_{\boldsymbol{w}_{\boldsymbol{y}}}$ & $\boldsymbol{X}_{\boldsymbol{w}_{\boldsymbol{x}}}+\boldsymbol{Y}_{\boldsymbol{w}_{\boldsymbol{y}}}$ & Siralama \\
\hline $\mathbf{A}_{\mathbf{1}}$ & 0,292 & 0,000 & 0,333 & 0,893 & 0,556 & 0,167 & 0,000 & 0,183 & 0,306 & 0,489 & 8 \\
$\mathbf{A}_{\mathbf{2}}$ & 0,000 & 0,590 & 0,000 & 0,000 & 0,111 & 0,000 & 1,000 & 0,236 & 0,333 & 0,569 & 7 \\
$\mathbf{A}_{\mathbf{3}}$ & 0,544 & 0,363 & 0,376 & 0,356 & 0,333 & 0,000 & 0,000 & 0,438 & 0,136 & 0,574 & 6 \\
$\mathbf{A}_{\mathbf{4}}$ & 0,494 & 0,363 & 0,430 & 0,226 & 0,444 & 0,000 & 1,000 & 0,429 & 0,456 & 0,885 & 4 \\
$\mathbf{A}_{\mathbf{5}}$ & 0,213 & 0,000 & 0,290 & 0,950 & 0,000 & 0,333 & 0,125 & 0,143 & 0,233 & 0,376 & 10 \\
$\mathbf{A}_{\mathbf{6}}$ & 0,169 & 0,000 & 0,462 & 0,279 & 0,778 & 0,500 & 0,250 & 0,160 & 0,486 & 0,646 & 5 \\
$\mathbf{A}_{\mathbf{7}}$ & 0,326 & 0,605 & 0,204 & 0,738 & 1,000 & 1,000 & 0,100 & 0,413 & 0,704 & 1,117 & 3 \\
$\mathbf{A}_{\mathbf{8}}$ & 0,544 & 0,000 & 0,376 & 1,000 & 0,222 & 0,000 & 0,000 & 0,293 & 0,167 & 0,459 & 9 \\
$\mathbf{A}_{\mathbf{9}}$ & 0,681 & 0,236 & 1,000 & 0,142 & 0,889 & 0,667 & 0,250 & 0,567 & 0,556 & 1,123 & 2 \\
$\mathbf{A}_{\mathbf{1 0}}$ & 1,000 & 1,000 & 0,140 & 0,576 & 0,667 & 0,167 & 0,500 & 0,828 & 0,458 & 1,285 & 1 \\
\hline
\end{tabular}

Tekstil işletmesi deposunda kullanılmak üzere alınacak, kapalı depo şartlarına uygun, 3 ton kaldırma kapasiteli, 10 farklı forklift alternatifi arasından en iyi alternatif $\mathrm{A}_{10}$ olarak belirlenmiştir. En son sırada yer alan alternatif ise $A_{5}$ olarak belirlenmiştir. Forklift alternatifleri arasındaki sıralama $A_{10}>A_{9}>A_{7}>A_{4}>A_{6}>A_{3}>A_{2}>A_{1}>A_{8}>A_{5}$ şeklinde elde edilmiştir.

\section{SONUÇ}

$\mathrm{Bu}$ çalışmada yeni bir ÇKKV yöntemi olan KEMIRA-M yöntemi ile forklift alternatifleri değerlendirilmiştir. Yöntem, kriterleri kendi içerisinde iki ve daha fazla gruba ayırıp öncelik sıralamasının uzmanlar tarafından yapılmasını gerektirdiği için çok fazla başlangıç bilgisi gerektirmemektedir. Sonrasında öncelikleri belirlenen kriterlerin ağırlıkları alınarak uygun alternatif belirlenmeye çalışılır. Diğer çalışmalardan farklı bir alan olarak bu çalışmada bir tekstil işletmesinin kapalı deposunda kullanılmak üzere 3 ton kapasiteli akülü forklift alımı için 10 alternatifin değerlendirilmesi KEMIRA-M yöntemi ile yapılmıştır. Depolama sitemlerinde kullanılan forkliftler depoların daha verimli kullanılabilmesi için yapılan yüksek raf sistemlerine insan gücünün yetmeyeceği ağırlıkları kaldırmak için oldukça önemli yer tutmaktadır. Bu çalışmada belirlenen yedi kriter, iç ve dış faktörler olmak üzere iki gruba ayrıldıktan sonra alanında uzman kişilerden kriterlerin sıralamasının yapılması istenmiştir. $\mathrm{Bu}$ aşamada uzmanların deneyimleri ve çalışma şartları ile bağlantılı olarak yapacakları kriterlerin öncelik sıralaması subjektif olacaktır. Alınan görüşler Kemeny medyan yöntemi ile uzmanların kriter sıralaması öncelikleri medyanı alınarak daha gerçekçi ve objektif olarak kriter öncelikleri 
sıralaması yapılmış olur. $\mathrm{Bu}$ çalışmada uzman görüşleri sonrasında öncelikleri belirlenen kriterlerin medyan değerlerine göre elde edilen öncelik sırasına göre dış kriterlerden garanti süresi, servis ağ1 ve marka güvenilirliği eşit önceliğe sahipken birim fiyat en düşük önceliğe sahiptir. Öncelikleri belirlenen iç kriterlerin medyan değerlerine göre; dış dönüş yarıçapı ve asansör yüksekliği eşit önceliğe sahipken, onları üst kabin koruyucu yüksekliği izlemektedir. Tekstil işletmesi deposunda kullanılmak üzere kapalı depo şartlarına uygun 3 ton kaldırma kapasiteli akülü forklift alım sürecinde 10 farklı forklift alternatifi arasından en iyi alternatif $A_{10}$ olarak belirlenmiştir. Forklift alternatiflerinin sıralamas $A_{10}>A_{9}>A_{7}>A_{4}>A_{6}>A_{3}>A_{2}>A_{1}>$ $\mathrm{A}_{8}>\mathrm{A}_{5}$ olarak elde edilmiştir.

KEMIRA-M yöntemi, kriterlerin iç ve dış faktörler olarak iki gruba ayrılabildiği ve her gruptaki kriter sayısının fazla olmadığı durumlar için uygundur. KEMIRA-M yöntemi, KEMIRA yöntemine göre daha kolay hesaplamalar içermektedir. Ayrıca bu yöntem özellikle kriter ağırlıklarını belirlemede kolaylık sağlar. Kriter ağırlıklarını belirlemede kullanılan AHP ve MACBETH gibi diğer yöntemlere göre daha az başlangıç bilgisine ihtiyaç duyması yöntemin bir avantajıdır. Yöntemin dezavantajı ise karmaşık, uzun işlemler içermesi ve aynı zamanda işlemlerin zaman alıcı olmasıdır.

Bundan sonraki çalışmalarda, forklift seçimi problemi diğer ÇKKV yöntemleri ile ele alınarak elde edilen sonuçlar kıyaslanabilir. KEMIRA-M yöntemi karmaşık hesaplamalar içerdiğinden dolayı uygulama aşamasında kolaylık sağlanması için bir yazılım geliştirilebilinir. Böylelikle günlük hayatta işletmeler açısından daha kolay kullanabilmesi sağlanabilir.

\section{KAYNAKÇA}

Atanasković, P., Gajić, V., Dadić, I. \& Nikoličić, S., (2013). Selection of Forklift Unit for Warehouse Operation by Applying Multi-Criteria Analysis, Promet - Traffic\&Transportation, 25(4), 379-386.

Hassan, M.M.D. (2010). A Framework for Selection of Material Handling Equipment in Manufacturing and Logistics Facilities, Journal of Manufacturing Technology Management, 21(2), 246 - 268.

Jahan, A., Edwards, K. L. \& Bahraminasab, M. (2016), Multi-Criteria Decision Analysis for Supporting the Selection of Engineering Materials in Product Design, Second Edition, Butterworth-Heinemann

Kosareva, N. Zavadskas, E. K., Krylovas, A. \& Dadelo, S. (2016). Personnel Ranking and Selection Problem Solution by Application of KEMIRA Method. International Journal of Computers Communications \& Control, 11(1), 51-66.

Krylovas, A., Zavadskas, E. K. \& Kosareva, N. (2016). Multiple Criteria Decision-Making KEMIRA-M Method for Solution of Location Alternatives, Economic Research-Ekonomska Istraživanja, 29(1), 50-65.

Krylovas, A., Zavadskas, E. K., Kosareva, N. \& Dadelo, S. (2014). New KEMIRA Method for Determining Criteria Priority and Weights in Solving MCDM Problem. International Journal of Information Technology \& Decision Making, 13, 1119-1133.

Kulak, O. (2005). A Decision Support System for Fuzzy Multi-Attribute Selection of Material Handling Equipments, Expert Systems with Applications, 29, 310-319.

Onut, S., Soner Kara S. \& Mert, S. (2009). Selecting the Suitable Material Handling Equipment in the Presence of Vagueness, International Journal of Advenced Manufacturing Technology, 44, 818-828.

Pamučar, D. \& Ćirović, G. (2015). The Selection of Transport and Handling Resources in Logistics Centers Using Multi-Attributive Border Approximation Area Comparison (MABAC), Expert Systems with Applications, 42(6), 3016-3028.

Park,Y.B. (1996). ICMESE: Intelligent Consultant System for Material Handling Equipment Selection and Evaluation, Journal of Manufacturing Systems, 15(5), 325-333.

Yaman, R. (2001). A Knowledge-Based Approach for Selection of Material Handling Equipment and Material Handling System Pre-design, Turkish Journal of Engineering and Environmental Sciences, 25, 267- 278. 